\title{
Continuing Professional Development: rhetoric and practice in the NHS
}

\section{Introduction}

The aim of this article is to discuss Continuous Professional Development (CPD) in the context of the NHS in the UK. CPD as a process is seen as a major mechanism on the agenda of reform in the NHS and therefore exploring the question of how CPD is perceived by staff can provide insights into the changing dynamics of the employment relationship in particular staffing and professionalism. The data presented in this article is derived from two related studies based on employment relations in NHS Wales from which the findings relevant to CPD are highlighted. The studies consisted of an initial, widely focused, quantitative stage, and a second more in-depth qualitative phase. The population researched for both studies focussed upon frontline clinical supervisors. This group were seen as a key group of professionals who operate in the front line delivery of health care services and who are pivotal in the enactment of NHS policy.

The key outcomes reported here highlight a series of tensions. First, although CPD is intended to provide a key role in NHS reform, there is an apparent disparity between the provision of and for CPD activities resulting in a perceived, and actual, shortfall in current systems and structures to meet the expectations of the organisation, relevant professional bodies and individuals. This disparity is highlighted particularly in terms of a move away from career planning towards a boundary less career model in relation to the group of clinical supervisors surveyed. Second, there is clear reluctance by this group of staff to take on managerial roles (with its attendant additional requirement for managerial skills development) against the alternative option of investing in the 
development of their clinical skills which, for some at least, has led to them falling into management roles without the necessary development rather than following a career plan into management thus adding a further level of complexity about CPD being a straightforward activity to engage with.

It is perhaps the absence of a 'thought through' approach in which the requirements for CPD to meet an organisational based role related to management, with its requirements for management development rather than a CPD approach focussed on mandatory professional training to remain registered or certified, which provides the greatest challenge.

The article is organised as follows. First we offer definition and a clarification for the term CPD and its variations. This is followed by a discussion about the NHS and its relationship with and expectation for CPD in terms of policy development. A description of method is followed by presentation of CPD related outcomes from a larger survey of NHS front line staff. This data is then discussed from the perspective of 19 in depth follow up interviews the purpose of which was to explore the attitudes of this key group of employees to the provision of and for CPD in the NHS Trust in which they were employed.

\section{Continual Professional Development}

The term 'CPD' is commonly used to describe a concept also denoted as 'Lifelong Learning', 'Continuing Education', 'Continuing Professional Education', 'Continuing Vocational Training', 'Continuing Education' and 'Post Qualification Development' (Houle, 1980; Tann, et al., 2001). 
The literature on CPD is largely devoid of an overarching narrative but it is possible to identify three main themes implicit in explanations of the motivation to adopt CPD: the first theme could be broadly described as organisational and is associated with a drive on the part of organisations to remain competitive. The second theme could be is associated with individuals gaining competence for advancement. The third theme is associated with the professions and in this theme, CPD is associated with a concern for updating to maintain professional competence.

Within the first theme, where organisational competitive considerations are considered, the literature identifies the need to maintain a strategic presence in an increasingly competitive and global market place as a key motivator for organisations to support CPD (Crockett \& Geale, 1995; Sandelands, 1998; Friedman et al., 1999).

Whereas in respect the second theme of career development, the literature identifies that this can be organisationally or individually driven, and where the latter is the case, it is linked to a desire on the part of individuals to 'get ahead' or achieve promotion (Barrington \& Wood 1988; Crockett \& Geale, 1995). This theme in the literature also tends to be associated with the adoption of individualistic boundaryless careers (Arthur \& Rosseau, 1996) to supplant the more traditional linear career planning processes (Sonnenfeld et al., 1992; Collin \& Young, 2000; Mainiero \& Sullivan, 2005).

Where the third theme of professional updating is concerned, the insufficiency of initial qualifications to ensure competence over time is one of the key prompts for CPD (Gear et al., 1994; Kennie \& Enemark, 1998). Often this theme is further 
couched in professional or organisation-based terms which advocate certification of professional competence. To this end some employers and some professional bodies require individuals to complete a minimum threshold of CPD each year to demonstrate that they are 'competent' professionals. For example, the Nursing and Midwives Council (NMC) will remove individuals from their register if 35 hours of compulsory CPD is not completed each year. This approach to CPD is described as a sanctionsbased approach and it contrasts with benefits-based approach used by other professional bodies and employers (eg the Society of Radiographers) (Rapkins, 1995).

These contrasting philosophies of CPD, whether sanctions or benefits-based, have led to a widespread consideration of the implications of a compulsory system of CPD within the literature (Madden \& Mitchell, 1993; Jones \& Fear, 1994; Friedman et al., 2000). Themes highlighted include difficulties in accommodating compulsory CPD and still achieving work-life balance (Welford, 2002); contradictions arising from compulsory-prescriptive approaches to CPD and the need to accommodate individuals' differences in speed of learning (Jenkins, 2002); acknowledgement that compulsory CPD may prove counter-productive in encouraging professionals who are coming up to retirement to remain in service during periods of recruitment crisis (Andalo, 2005); contradictory philosophies of self development within CPD and compulsory assessment of learning as adopted by some professional bodies (Carey, 2004); concern that whilst CPD is often used as a indicator of learning and competence, CPD and competency are not necessarily synonymous (Bourner, 2003) with some professionals seeing CPD as a 'points-gathering exercise' (Phillips \& Friedman, 2001); resourcing constraints, and the ability of members of a 'profession', regardless of their work situation, to access and attend CPD events (Garavan, 1998; Evans, 2002). 


\section{The NHS and CPD}

The NHS is the third largest public sector employer in the world, behind the Indian Railways and the United States Department of Defence (Hansard, 2006). Within the UK, it is organised in regions, one of these being Wales. NHS Wales employs approximately 81,000 staff and commands a budget of $£ 2.8$ billion (Bourn, 2005). It provides four types of care grouped into Trusts i.e. primary (general practice, dentists, pharmacy and optical), secondary (hospital and ambulance services), tertiary (specialist centres treating pathologies and diseases) and community (home based care provided in partnership with social services) (Parry, 2003; Bourn, 2005).

All the Trusts in Wales have CPD related policies and in many cases these are wedded to human resource management (HRM) policy infrastructures (Barrington \& Wood, 1988). Although it is difficult to make a categorical case for CPD's contribution to organisational performance or patient outcomes (Waddell, 1993; Brown, et al., 2002; Lawton \& Wimpenny, 2003), it is nevertheless stated and implied in a range of policy documents relating to the NHS (produced, for example, by the Department of Health, the Modernisation Agency, as well as by the Scottish Assembly and National Assembly for Wales). The consensus is that the most effective mechanism for ensuring the protection of the public is an initial registration with the relevant professional body on qualification and then continuous maintenance and updating of competence through professional development (Department of Health, 1999; Scottish Executive, 2001).

This emphasis on professional competence is highlighted by an extract from a Welsh 
Assembly document discussing nursing (2000, p.1):

The ability to deliver nursing ... services depends fundamentally on the way in which practitioners are prepared, both during their initial education ... and in their post registration education and CPD.

Despite this emphasis in the NHS that CPD is synonymous with competence, increasingly there is a move towards restructuring of clinical provision to enhance patient outcomes while at the same time increasing the efficient use of professional staffing resources (Mole et al., 1997; Scally \& Donaldson, 1998; Bourn, 2005).

This modified approach to CPD is apparent from the following guidance from the

Department of Health (1999):

In planning or providing CPD, NHS organisations should ensure that, besides fully involving the individual and other stakeholders, it is part of a wider organisational development plan in support of local and national service objectives focused on the development needs of clinical teams, across traditional professional and service boundaries. (Department of Health, 1999).

Accompanying this theme is an implied perception that traditional job structures may

be impeding improvements in the service is also spelt out in other Department of

Health policies:

Changes in working practices will be fundamental to delivering improvements. The way staff are employed and paid in the NHS retains too many of its 1940s employment practices - overly demarcated and inflexible... (Department of Health 2002, p.34).

This is also apparent in the 2003 NHS document 'Agenda for Change' [emphasis added]:

[The Agenda for Change] ... will ensure fair pay and a clearer system for career progression. For the first time staff will be paid on the basis of the jobs they are doing and the skills and knowledge they apply to these jobs.... To support personal development and career progression, there will be a new knowledge and skills framework linked to annual development reviews and personal development plans. The system is designed to replace outdated demarcations allowing staff to progress by taking on new responsibilities. This will allow jobs to be designed around patient and staff needs, improving overall productivity and the job satisfaction for staff (NHS Modernisation Agency, 2003, p.1). 
These themes which underlie the key role which CPD is anticipated to play in the NHS suggest possible tension; namely that CPD is assumed necessary to ensure health professionals in the NHS remain competent but that CPD is also a mechanism used to transact organisational reform for the sake of greater efficiencies.

The data here reported provides a useful context for existing literature on CPD insofar as it examines the extent to which the twin aims of CPD reflected in NHS related policy documents, namely CPD for professional development, and CPD for the enhancement of efficiencies, is experienced at 'grass roots' level. At present, there appears to be no literature describing the extent to which organisations like the NHS are committed to support the emerging types of CPD suggested by the need to implement policy. Nor does there appear to be much description as to how professional (in this case clinicians') perceptions of this CPD. Since a comprehensive investigation of the state of CPD throughout the NHS is beyond the scope of this work, the parameters of the research are limited to providing an insight into the experiences of one typical group within the NHS, namely frontline clinical supervisors.

\footnotetext{
Method

The primary research drew upon data collected as part of wider studies into employment relations in five NHS trust hospitals in Wales and focuses upon frontline clinical supervisors. This category of staff includes F-grade and higher nurse managers, podiatrists, occupational therapists, public health nurses, physiotherapists, speech therapists, radiographers and dieticians. Whilst it could be argued that the findings from this study may not be generalisable to the whole of the NHS, supervisory level clinical staff are both a numerically large group of staff and the first level of
} 
interface between the front line employees and the employing organisation.

Two methods of data collection were utilised in this study. The majority of the data was collected through the use of a questionnaire which utilised Likert scales and which was designed to explore employment relationships in general including themes such as trust, communication and CPD in particular. The questionnaire was distributed to 2500 staff in all levels of the NHS in Wales and 1837 usable responses were received.

The relevant (CPD related) data from the questionnaire was subjected to two forms of analysis. The overarching disposition of the data was established through simple descriptive statistics and the significance of the results for each question was established through the use of an ANOVA-based comparison between 'frontline clinical supervisors' and 'other clinically related staff' in the organisation. The findings from the questionnaire were then further explored using semi-structured interviews ( $\mathrm{n}=19$ ) whose purpose was to further explore the significant results highlighted.

Non-probability sampling was used in the selection of interview participants to overcome difficulties in gaining access to key informants given that these staff were relatively senior post-holders with great time pressures (Crimp and Wright, 1995).

In respect to the approach to interviewing, after confidentiality assurances, and general introduction to the research project, respondents were engaged in semi-structured interviews about employment relations in their organisation in general and this included questions about their experience of CPD in the NHS and their understanding 
of their subordinates' perception of CPD in the NHS, in particular. Interviews lasted an average of sixty minutes and each interview was audio recorded and transcribed, and in the process anonymised. Each respondent was invited to amend the transcriptions before they were added to the research data.

In terms of coding the interview results, two concurrent methods were adopted. First, answers were noted against the structured questions provided in the interview and then second a small group of researchers worked independently to undertake content analysis and code the transcriptions. This group then met and agreed a consensus of the coding.

\section{Results}

The total number of questionnaires distributed was 2500 . There were 1837 usable returns. Of these returns, 1029 were from respondents involved in clinical activities. Of the 1029 clinical staff, 22 were in upper management, 744 were other support staff (including 135 non-clinical supervisors), 269 were clinical supervisors, 135 non-clinical supervisors and 609 other support staff.

The first analysis compared supervisory-level clinicians $(n=269)$ against 'all clinically related staff' $(n=1029)$. The findings from the data analysis highlight three areas. First, there is a lower level of acceptance amongst supervisory- level clinicians than among non supervisory clinically related staff' that learning and development is the responsibility of the individual. Second the supervisory-level clinical staff are more likely to be satisfied that they have the resources necessary to perform their jobs well than other levels of clinically related staff and third, the supervisory-level clinical staff report feeling less challenged by their work than other clinically related staff. 


\section{<<Take in Table I here >>}

The second ANOVA test compares the results for the 'supervisory-level clinicians' subject group ( $\mathrm{n}=269)$ with the results for 'non-clinical supervisor group' $(\mathrm{n}=135)$ producing just one statistically significant difference - that being that the finding that supervisory level-clinical staff are significantly more likely than non-clinical supervisory staff to believe that 'learning and development is an individual's responsibility'.

\section{$<<$ Take in Table II here >>}

In order to probe these significant findings more fully the in-depth semi-structured interviews were conducted with a sample of nineteen respondents who were supervisory level clinicians. Respondents' related comments were grouped within four categories.

\section{(a) Respondents' experience of CPD for their current managerial role}

The majority of respondents (16 out of 19) reported having had no formal training for their managerial roles until some time (between 6 months and 15 years) after they were in post. One respondent (R19) reported having had no formal training for a managerial post at all, having only had on the job experience. In the words of this respondent:

"I had absolutely no preparation for my current role whatsoever" (R19).

When asked how they had come to their current post, all respondents explained the evolution of their careers since the time they trained as a nurse or professional/ practitioner. For all the respondents, the first post had been in the NHS and all 
respondents focused on the good fortune and instrumental choices that had led them to their present position. The fact that they may have aspired to becoming a supervisor or manager was something absent from their narratives, a typical comment being:

"we had a meeting as a team (about the vacancy) and I was less reluctant than others, I went for the post and got it" (R14).

All respondents held clinical qualifications of various types ranging from undergraduate certificates $(n=4)$, diplomas $(n=7)$ and bachelors degrees $(n=4)$ through to clinical masters degrees $(n=4)$. Few respondents had gained academic qualifications in management: one respondent had an MBA and several had completed certificates or diplomas in management $(n=5)$.

\section{(b) The nature / extent of the formal career planning received by respondents}

In terms of formal career development planning, most respondents reported being totally unprepared for their managerial roles. The respondents identified this lack of preparedness as arising largely from having received no formal career planning from their employer:

“I don’t think I was prepared personally or professionally for some of the changes" (R2).

"I had absolutely no preparation for my current role whatsoever" (R19).

However one respondent did identify that they had experienced career planning in the form of a supervisor selecting her as a successor:

"when I look back now without a doubt from the minute she recruited me she had me earmarked that within a year she would retire and I would take over. I 
can still feel her finger in the small of my back pushing me towards applying for that position" (R14).

Problems arising from the lack of career planning had manifested themselves to respondents in different ways. Some respondents identified this as the source of uncertainty in terms of whether to priorities the maintenance of clinical skills, or whether to prioritise those of management. In the absence of clear guidance, the potential for indecision and career choice error was significant. As one respondent commented:

"There is an issue about whether I [should] be playing out a clinical role to reregister, to be seen as competent, to give the right advice or, do we have to acknowledge that that realistically this can't happen if I pursue my career in a management role?" (R5).

A further issue identified the insufficiency of the learning and development offered by the NHS and the fact that many had not received any formal input related to management and were therefore frequently unsure as to how to behave in a management role. They were also concerned that their previous clinical training may have inculcated a set of values that was at odds with those of management:

"if I wanted any more responsibility I would want some more training about, or some more supervision on, how to meet those targets. I think there are certain things that we cannot [do], we can meet some targets but there are some other priorities that actively work against you meeting other targets such as patient care" (R9).

\section{(c) Experience of CPD with the current employer}

The theme most commonly mentioned by all respondents was the lack of resources for CPD purposes. Most recognised a mutual inconsistency between the professional bodies' insistence on CPD for maintenance of credentials, the organisation's emphasis on CPD for effectiveness and the actual resources available for CPD. This inconsistency was perceived to be exacerbated by the fact that CPD and its attendant 
demand for supporting resources tended to be considered alongside annual leave, sickness and health and safety as an obligation that departments and service areas should support but without additional resources being made available.

All acknowledged the necessity of CPD and the fact that over the period of their employment with their current Trust, they had been involved in CPD of various types. Some respondents understood CPD to mean having undertaken formal learning and development and others understood it in a wider sense to also involve on-the-job learning and reflection on practice.

Virtually all of the respondents discussed the requirement of their Trust that some mandatory training be undertaken. Indicative aspects of the mandatory training required for clinical staff included CPD in manual handling, infection control, fire evacuation, and health and safety. But, with regards to opportunities to undertake nonmandatory learning and development, responses were more mixed with most respondents identifying such development as important to their professional competence but not as freely available as they would have liked due to resource / financial constraints.

Although it should be noted that the reluctance or inability on the part of NHS Trusts to fund learning and development was not thought to be universal, each Trust cited was reported as having an unstated rationing mechanism for development monies. The rationing was either decided according to competitive pressures in a given year or according to the extent to which the request for training fitted in with the Trust's objectives. 
In terms of the way Trust objectives could act as a constraint, it was apparent that, even where resources were available, line managers in some Trusts were blocking their staff's access to CPD because of their greater concerns over meeting clinical targets and sustaining standards of care:

“...sometimes there's not enough time to treat patients... all the staff ... have their personal development plans.... But... at the end of the day it's the patient care that comes first..." (R17).

The pressure to meet targets was implicit in the observation that "heads start to roll"

(R3) if targets are not met.

The fear of not performing was cited also as a factor in staff not taking secondments:

"I think a lot of it is the uncertainly around taking secondments in the current climate. With the agenda for change coming in theoretically October 2004, lots of people [are] not wanting to make the move out" (R19).

Other barriers to undertaking CPD included insufficient time because of family

commitments:

"As I've been bringing up a young family for the last eleven years then obviously given my own personal time it has been very challenging but it's almost been a guilty feeling and a concern that I haven't got anything formalised" (R5)

Several consequences of the lack of CPD in the NHS were cited. One was frustration and de-motivation:

"Clinical development: you do it off your own back. It's supported in the sense that you do it in your own time and with your own money, so how supportive that is, is debatable" (R3).

"Everybody is responsible for taking on board their own professional development..." (R6).

(d) The management of CPD for subordinates 
As supervisors, the respondents felt that they had clear obligations in terms of managing their staff's CPD. The theme most recurrently discussed by all respondents was the issue of lack of resources for CPD purposes.

“....we have about $£ 2000$ for training for 55 people. We have no extra staffing for annual leave, training, sickness. We are supposed to have about $20 \%$ extra staff to cover this but when you add it up annual leave takes up $16 \%$ so once you take off your mandatory training and the things you've got to do, you're actually left with very little for professional development. The way budgets are done this is never going to be adequate..." (R13).

"we haven't got sufficient funding in order to manage ...it's a professional issue since we have to do it for our professional status, our professional registration..." (R19)

But some respondents also explained that the shortage of resources often resulted in dysfunctional 'collection oriented' approaches to CPD among their staff:

"I think they like to see people with pieces of paper to say that they've done something" (R11).

"...staff tend to think that you've got to go to a course, get a certificate at the end and that's your learning" (R18)

These comments tended to mirror the respondents' own concerns regarding the necessity but lack of availability of CPD so that, despite being managerial agents of their organisations, many respondents went to lengths to disassociate themselves from the rationed state of CPD within their Trust.

However it must be noted that the definitional possibility that CPD could consist primarily of reflection and on the job learning rather than formal certificated learning was shared by only one respondent, with the others stressing the importance of supplementing these methods with formal learning. Where some formal learning was concerned, however, there was frequently an opinion expressed that CPD on offer in the trusts was too academic and not sufficiently practical: 
“...particularly the degree courses: we're moving into degree now and not diploma” (R6)

There was also a concern that tying CPD and career development to reform initiatives

(like Agenda for Change) in a semi-mandatory manner may not be feasible in the long term:

"the first thing that the [staff] said when they looked at their [new Agenda for Change] job descriptions is 'are we going to be given time to do all that CPD?" (R14).

Four respondents identified that by embedding CPD into job design and mandatory practice and at the same time raising the threshold of starting qualification in some professions, there will be a contraction of the labour pool as some people who are either not academic or ambitious are driven out.

\section{Discussion}

In terms of the employing organisation and policy makers, through the measures referred to and consistent reference in policy development, the organisation imbues front line clinical supervisors with a clear sense of how important they are through highlighting them as a key group to be engaged with. These references place them at a central point for organisational reform thus making them a suitable group with which to explore the current position relating to this group's perceptions of CPD and the implications this may have for retaining commitment amongst this key group.

In the Introduction section of this article the key findings were framed and then explored in terms of the survey data and follow up interviews. The aim of this discussion section is to unravel and further explore the underlying issues. In order to further consider the drivers for CPD it is worth reflecting upon the group who provide the focus of this article and what the reasons might include which lead to them to see 
themselves as professionals. In this there are three main perspectives; the individual, the employing organisation and by association the policy makers, and the professional bodies.

What it means to be a professional in the NHS is a question worthy of a more in depth research effort. On the basis of the research reported it was not clear whether or not this perception related to their level of responsibility or the time it took them to train or become qualified (with its attendant requirements to record CPD for professional body accreditation). And in so doing whether or not it (CPD) becomes both ingrained as personal activity to participate in and also as an expectation which should be provided as an accompaniment by the employer to the job role. Or more simply because of the supervisory responsibility which accompanied the role and which differentiated the role through the involvement of a higher degree of autonomy than the staff they are responsible for. This suggests a comparison with the individuals supervised who may not be qualified to the same extent and offers a contrast between being thought of as an independent self motivated learner rather than a learner trained to follow routine and procedures.

A willingness to engage with and a responsibility for investing in personal learning and development have been argued as a feature of what it means to be a professional. The contention has been that being (identified as) a professional leads to a higher degree of autonomy and therefore remuneration. The results from the quantitative survey revealed a higher level of acceptance that CPD is the responsibility of individuals amongst supervisory-level clinicians than among the 'all clinically related staff' group. The initial data also revealed that supervisory-level clinicians believed they had the 
organisation based resources necessary to perform their own jobs well. However this finding does not match the responses of the supervisory-level clinicians in the follow up interviews. Here many respondents reported either a feeling guilt for failing to undertake sufficient CPD or reported paying for formal CPD themselves. Two possible explanations for this apparent contradiction appear possible. First, supervisory-level clinicians have a higher awareness of the resource constraints faced by the organisation and consequently have a lower expectation about what resources they can 'reasonably' expect from their employer to foster CPD (Hemmington, 2000). Second, if supervisory-level clinicians tend to see themselves as semi-autonomous professionals then they might assume responsibility for their own learning and competencies rather than looking for their employer to provide these resources (Jones \& Robinson, 1997).

Support for the latter interpretation might also be found in the findings from the supervisory-level clinicians included in the in-depth interviews. Here the majority (16 out of 19) reported having received no formal training for their managerial roles until some time (between 6 months and 15 years) after they were in post. Similarly, in terms of formal career development planning, most of these respondents reported being totally unprepared for their managerial roles. The respondents identified this lack of preparedness as arising largely from receiving little or no preparation or formal career planning from their employer. The in-depth interviews also revealed that respondents perceived that career development was given a low or nil priority in the Trusts represented and yet the documentary analysis indicated majority of the Trusts not only had a policy for career development (usually in the form of personal development planning) but were also committed to a process of succession planning. It further 
appears possible that employees still expected a traditional linear career planning process (Sonnenfeld et al., 1992; Collin \& Young, 2000) while the Trusts might have moved albeit unwittingly to accept the individual centric boundaryless careers model (Arthur \& Rosseau, 1996; Mainiero \& Sullivan, 2005).

A number of consequences follow from the apparent adoption of a form of boundaryless career model by NHS Trusts. First, in implicitly or explicitly shifting the onus for career planning to individuals, the NHS Trusts run the risk of not having sufficient succession planning in place for their future needs. Second, the shift to individualised career planning may produce individualistic anomie (Elwell, 2005) and a perceived breach of the traditional psychological contract (Guest, et al., 1996). Traditionally the psychological contract carried with it expectations of promotion (Hilltrop, 1995) and the usual type of career progression employees will have come to expect in a large organisation like the NHS. Movements away from the traditional model have altered the balance of progression being mainly upwards focussed in favour of lateral career development (ibid) and created uncertainty about who might be responsible for career development and progression given the traditional historical well structured processes which have been in place since the inception of a national health service.

The concern most commonly mentioned by respondents was the lack of resources for CPD purposes. In general terms, is also apparent that responses to the questionnaire reveal a perception held by clinically related staff that there was an insufficiency of resources for CPD purposes. This may highlight a potential for Trusts to ration CPD resources. Such a position would appear to be at odds both with the organisational 
rhetoric concerning the importance of $\mathrm{CPD}$, and at odds also with the requirement of some clinically related staff to undertake mandatory professional updating to remain registered or certified. Most respondents in the in-depth interviews recognised a mutual inconsistency between the professional bodies' insistence on CPD for maintenance of credentials, the organisation's emphasis on CPD for effectiveness and the actual resources available for CPD (Furze \& Pearcey, 1999). The confusion amongst interview respondents as to why Trusts might emphasise the requirement for CPD and yet make formal learning and development difficult to pursue can be summed up by one respondent “...it just isn't fair” (R8).

It is also worth commenting upon perceptions about identity both as an individual and in terms of identifying with a professional group. This contributes a further level of uncertainty related to maintaining this identity. Perceptions of self, as in a professional role, involves a clear sense of identity and associated expectation that the employing organisation did not or was not prepared to consider in terms of the expectation by individuals of CPD and its purpose in sustaining professional identity

This brings the discussion to the expectations of professional bodies for their members to engage in CPD. In an examination of the narratives what comes through very strongly was the level of frustration felt with the current arrangements for CPD targeted at the organisation and not at the professional bodies. It has long been argued (Larson, 1977) that professions create a market and generate organisations and institutions to support this market, evidenced through, for example, closure by creating a boundary around the profession to decide who does or does not continue to practice and the main mechanisms for this have been higher level academic based entry qualifications and 
maintaining up to date professional practice through CPD mechanisms. It is inevitable that, as professionals progress in their chosen career, they will increasingly gain 'management' responsibility. The more specialised the role the more 'professional' the perception and the more interest professional bodies have in the work group which employ their potential members. Increasingly professions are recognising management skills as relevant and valuable areas of development for their practitioners and yet the emphasis with this group of professionals appears to be on maintaining and developing clinical skills related to their particular profession rather then on equipping them for career progression. Professional bodies cannot distance themselves from taking some responsibility for the current position

The issues which arise from the above highlight the disparity between NHS reform and CPD. The move away from career planning to a boundaryless career model is a significant development. The responsibility for identifying and taking action related to CPD should in fact rest with the individual rather than the organisation yet there is a clear unresolved tension if through policy development the organisation seeks operational efficiency through CPD. The onus of responsibility to provide resources to sustain it then falls to the organisations to provide. There is clear lack of understanding by the organisation about the continuing level of commitment made by individuals or perhaps a more cynical attempt to reduce costs invested in higher level training and development provision.

The reluctance of the members of this group to take on managerial roles against the alternative option of developing their clinical skills has resulted in them entering management roles by default rather than following a career plan into management. 
This adds a further level of complication to the dissuasion about CPD being a straightforward activity to engage with. The way in which policy has been created/developed and disseminated has caused a lack of clarity between CPD and management development for career progression and who might be responsible for following through on delivery. It is perhaps the absence of a thought through approach in which the requirements for CPD to meet the changing organisational based role for example related to management development rather than CPD which is focussed on mandatory professional training to remain registered or certified which provides the greatest challenge

The potential negative outcomes associated with resource constraints for CPD and individualisation of career development in the NHS have been largely ignored by the academic literature, the professional bodies, the Trusts and the government. The evidence presented here suggests that Trusts, professional bodies and government, in particular, need to critically consider whether the assumed gains underpinning the rhetoric of CPD are gains in actuality and whether individualisation of responsibility for career development is a sensible future direction for the NHS given its potential to contribute to staffing problems for example recruitment, retention, disillusionment and dissatisfaction, with resultant overall reductions in performance over time within the NHS.

\section{Conclusions}

If the policy makers are correct in their assumptions that workplace reform in the NHS requires $\mathrm{CPD}$, and if the issues and problems identified here with CPD are representative of the situation in the NHS, then one might predict that those elements of 
the change programme that rely upon workplace reform (i.e. the NHS plan, the Modernisation Agenda and Agenda for Change) may not be as successful as anticipated. One of the key points upon which this suggestion turns is the gap between the organisational and institutional rhetoric on CPD and the practice as experienced amongst clinical staff. This gap has clear implications to impact the professional development and career development of clinical supervisors and their subordinates with its attendant impact on the psychological contract among professional employees within the NHS (Guest et al., 1996).

Ultimately, the failure to provide CPD in the way that clinically related staff in the NHS expect could impact negatively on the NHS Trusts' abilities to operate, given their reliance on a certified and registered workforce. It could also impact negatively on the motivation of individuals working within those Trusts. Therefore the task that faces the NHS and the professional bodies now must be to address the gap that exists between the actual and perceived position of the group under discussion with regard to CPD in particular but to also consider those other employee groups who may be similarly affected.

\section{Further work}

Future work could usefully replicate the research described here in different sectors (clinical and otherwise), hierarchical groupings and regions of the NHS.

\section{References}

ANDALO, D. (2005) How the new contract and changes to the register may affect recruitment. The Pharmaceutical Journal, 274, pp201-202.

ARTHUR, M. B. \& ROSSEAU, D. M. (eds.) (1996) The boundaryless career: a new employment principle for a new organisational era. (Oxford, Oxford University Press).

BARRINGTON, H. \& WOOD, S. (1988) Continuous development: people and work - a statement. (London, IPD). 
BOURN, J. (2005) The finances of NHS Wales 2005. Report by the National Audit Office Wales on behalf of the Auditor General for Wales. Available online http://www.wales.nhs.uk/documents/agw2004_11.pdf (Accessed 1 April 2006)

BOURNER, T. (2003) Assessing reflective learning. Education and Training, 45, (4/5), pp267-272.

BROWN, C. A., BELFIELD, C. R. \& FIELD, S. J. (2002) Cost effectiveness of continuing professional development in health care: a critical review of the evidence, British Medical Journal, 324, pp 652-655.

CAREY, J. (2004) CPD - Is it here to stay? Eyesight Professional. Available online http://www.eyesite.co.za/prodiscussions3.asp?mainbutton=professional\&navbutton=dis cussions (accessed 31 March 2006)

COLlin, A. \& YOUNG, R. A. (eds.) (2000) The future of the career. (Cambridge, Cambridge University Press).

CRIMP, M. AND WRIGHT, L. (1995) The market research process, (London, Prentice Hall).

CROCKETT, H. \& GEALE, J. (1995) The lone professional. In Clyne, S.

Continuing professional development. (London, Kogan Page).

DEPARTMENT OF HEALTH (1999) Making a difference: strengthening the nursing, midwifery and health, visiting contribution to health and healthcare. (London, The Stationery Office),

DEPARTMENT OF HEALTH (2002) Delivering the NHS Plan. Next steps on investment, next steps on reform. Available Online

http://www.publications.doh.gov.uk/deliveringthenhsplan/deliveringthenhsplan.pdf (Accessed 31 March 2006).

ELWELL, F. (2005) Glossary of sociology. Available online http://www.faculty.rsu.edu/\% 7Efelwell/glossary/Index.htm (Accessed 23 April 2006)

EVANS, I. R. (2002, 7 March 2002) Mandatory CPD, in Discussion Forums. The IEE.

http://www.iee.org/forums/forum/messageview.cfm?catid=163\&threadid=862\&STAR TPAGE=2\&enterthread=y (Accessed 31 March 2006).

FRIEDMAN, A., DURKIN, C., AND PHILLIPS, M. (1999) CPD surveys from professional association - further analysis. Available online http://www.pam.org.uk/uploads/cpd (Accessed 28 March 2008).

FRIEDMAN, A., DURKIN, C., AND PHILLIPS, M. (2000), CPD: What are the true costs of continuing professional development?, Continuing Professional

Development Journal, 3, pp 78-87 
FURZE, G. \& PEARCEY, P. (1999) Continuing education in nursing: a review of the literature, Journal of Advanced Nursing, 29, (2) pp 355-363.

GARAVAN, T. (1998) In-career professional development: the case of Irish secondlevel teachers. Journal of European Industrial Training, 22, (9) pp 375-385.

GEAR, J., MCINTOSH, A. \& SQUIRES, G. (1994) Informal learning in the professions, (Hull, University of Hull).

GUEST, D., CONWAY, N., BRINER, R. \& DICKMAN, M (1996), The state of the Psychological contract in employment: Issues in people management, (London. Institute of Personnel and Development),

HANSARD (2006) written proceedings of the House of Commons, available at http://www.publications.parliament.uk/pa/cm200506/cmhansrd/cm060622/text/60622w 1174.htm (accessed 31st October 2006)

HEMMINGTON, N. (2000) Barriers and drivers to CPD, Continuing Professional Development Journal, 3, (1) pp 23-31.

HILLTROP, J. M. (1995), The changing psychological contract: the human resource challenge of the 1990s, European Management Journal, 13 (3), September, pp286-94

HOULE, C. O. (1980) Continuing learning in the professions. (London, Jossey-Bass) JAESCHKE, R, SINGER, J, AND GUYATT, GH (1990), A comparison of 7-point and visual analogue scales: data from a randomized trial, Control of Clinical Trials, 11 (1), pp43-51

JENKINS, P. (2002) Fit the courses to the horses. The Pharmaceutical Journal, 268, (7191), pp465-468

JONES, N. \& ROBINSON, G (1997) Do organisations manage continuing professional development? Journal of Management Development, 16, (3) pp 51-61.

JONES, N. \& FEAR, N. (1994) Continuing professional development: Perspectives from human resource professionals, Personnel Review, 23, (8) pp 49-61.

KENNIE, T. \& ENEMARK, S. (1998) The growing importance of CPD. Continuing Professional Development, 1, (4) pp 156-167.

LARSON, I.M.S. (1977) The rise of professionalism: A sociological analysis. Berkeley, University of California.

LAWTON, S. \& WIMPENNY, P. (2003) Continuing professional development: a review, Nursing Standard, 17, (24) pp 41-44.

MADDEN, C. A. \& MITCHELL, V. A. (1993) Professions, standards and competence. A survey of continuing education for the professions. (Bristol, Bristol University). 
MAINIERO, L. A. \& SULLIVAN, S. E. (2005) Kaleidoscope careers: and alternative explanation for the "opt-out" revolution. Academy of Management Executive, 19, (1), pp106-123.

MOLE, V., DAWSON, S., WINSTANLEY, D. \& SHERVAL, J. (1997) Transforming the National Health Service. The challenge for career management. Journal of Health, Organisation and Management, 11, (3) pp 157-167.

NATIONAL ASSEMBLY FOR WALES (2000) Creating the potential - a plan for education. Briefing paper 1 from realising the potential. A strategic framework for nursing, midwifery and health visiting in Wales into the 21st Century.

Available online

http://www.wales.gov.uk/subihealth/content/keypubs/realisingthepotential/realisinge.pdf (Accessed 31 March 2008).

NHS MODERNISATION AGENCY (2003) What is Agenda for Change in plain English? Available online http://www.modern.nhs.uk/agendaforchange/Afcplain.pdf (Accessed 31 March 2008).

PARRY, P. (2003) Understanding the NHS in Wales. The Pharmaceutical Journal, 217, pp177-179.

PHILLIPS, M. \& FRIEDMAN, A. (2001) CPD: individual professional learning in practice. Research summary A study of the barriers and drivers to participation in continuing professional development. Professional Associations Research Network. Available online http://www.parn.org.uk/cpd/ipl/research_summary.pdf (Accessed 31 March 2006)

RAPKINS, C. (1995) Professional bodies and continuing professional development. In Clyne, S. (ed) Continuing Professional Development: Perspectives on CPD in Practice, (London, Kogan Page).

SANDELANDS, E. (1998) Emerging issues in continuing professional development. Continuing Professional Development 1, (2) pp 74-84.

SCALLY, G. \& DONALDSON, L. (1998) Clinical governance and the drive for quality improvement in the new NHS in England, British Medical Journal, July, pp 61-65.

SCOTTISH EXECUTIVE (2001) Caring for Scotland: the strategy for nursing and midwifery for Scotland. (Edinburgh, Scottish Executive).

SONNENFELD, J., PEIPERL, M. \& KOTTER, J. (1992) Strategic determinants of managerial labour markets. In Salaman, G. Human resource strategies. (London, Sage).

TANN, J., BLENKINSOPP, A. \& PLATTS, A. (2001) Teaching and learning at the leading edge: leading edge practitioners in community pharmacy, Management Learning, 32, (2), 163-179 
WADDELL, D. (1993) The effects of continuing education on nursing practice: a metaanalysis. Journal of Continuing Education in Nursing, 23, (4) pp 164-168.

WELFORD, J. (2002) Keeping the work-life balance - and then there's CPD. Journal of the Career Development Group, 5 (3/4). Also available on line

http://www.careerdevelopmentgroup.org.uk/impact/summer02/impact.htm

(Accessed $14^{\text {th }}$ February 2007) 
Table 1 Comparison between 'All other staff' and 'Supervisory-level clinicians'

\begin{tabular}{|c|c|c|c|c|}
\hline \multicolumn{2}{|c|}{ Questions } & \multirow{2}{*}{ 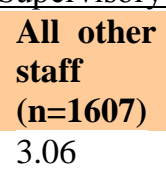 } & \multirow{2}{*}{$\begin{array}{l}\text { SLC } \\
(\mathrm{n}=\mathbf{2 6} \\
\text { 9) } \\
2.69\end{array}$} & \multirow{2}{*}{$\begin{array}{l}\begin{array}{l}\text { Significance } \\
(<.05 \\
\text { significant }) \\
.000\end{array}=\end{array}$} \\
\hline & $\begin{array}{l}\text { Learning and development is an } \\
\text { individual's responsibility }\end{array}$ & & & \\
\hline Q2. & $\begin{array}{l}\text { I have access to the training and } \\
\text { development opportunities I need to do my } \\
\text { job well. }\end{array}$ & 3.57 & 3.43 & .132 \\
\hline Q3. & $\begin{array}{l}\text { I have the resources I need to do my job } \\
\text { well. }\end{array}$ & 3.86 & 4.22 & .000 \\
\hline Q4. & $\begin{array}{l}\text { Chances of promotion in the Trust are } \\
\text { improved by working longer hours. }\end{array}$ & 4.73 & 4.73 & .954 \\
\hline Q5. & $\begin{array}{l}\text { I have unmet training needs on safety } \\
\text { issues }\end{array}$ & 4.26 & 4.18 & .378 \\
\hline Q6. & I feel valued at work & 3.68 & 3.72 & .191 \\
\hline Q7. & I feel positively challenged at work & 3.40 & 3.04 & .000 \\
\hline Q8. & $\begin{array}{l}\text { It is easy to maintain a work-life balance in } \\
\text { the Trust }\end{array}$ & 3.96 & 4.10 & .127 \\
\hline Q9. & $\begin{array}{l}\text { I am tempted to seek a job in a different } \\
\text { NHS Trust }\end{array}$ & 4.42 & 4.60 & .095 \\
\hline Q10 & $\begin{array}{l}\text { I am tempted to seek a job outside of the } \\
\text { NHS }\end{array}$ & 4.46 & 4.57 & .321 \\
\hline Q11 & $\begin{array}{l}\text { Personal achievements and successes are } \\
\text { acknowledged by the Trust }\end{array}$ & 4.15 & 3.98 & .066 \\
\hline Q12 & $\begin{array}{l}\text { Decisions made by managers reflect the } \\
\text { mission, objectives and values of the Trust }\end{array}$ & 3.72 & 3.62 & .426 \\
\hline Q13 & My values match those of the Trust & 3.48 & 3.38 & .239 \\
\hline
\end{tabular}


Table II Non-Clinical Supervisor level Group compared with Supervisory-level clinicians'

\begin{tabular}{|c|c|c|c|c|}
\hline \multicolumn{2}{|c|}{ Questions } & \multirow{2}{*}{$\begin{array}{l}\begin{array}{l}\text { NCSLG }^{\mathbf{1}} \\
(\mathbf{n}=136)\end{array} \\
3.35\end{array}$} & \multirow{2}{*}{$\begin{array}{l}\text { SLCS } \\
(\mathbf{n}=\mathbf{2 6} \\
\mathbf{9 )} \\
2.69\end{array}$} & \multirow{2}{*}{$\begin{array}{l}\text { Significan } \\
\text { ce }(<.05= \\
\text { significant } \\
) \\
.000\end{array}$} \\
\hline Q1. & $\begin{array}{l}\text { Learning and development is an } \\
\text { individual's responsibility }\end{array}$ & & & \\
\hline Q2. & $\begin{array}{l}\text { I have access to the training and } \\
\text { development opportunities I need to do my } \\
\text { job well. }\end{array}$ & 3.35 & 3.43 & .434 \\
\hline Q3. & $\begin{array}{l}\text { I have the resources I need to do my job } \\
\text { well. }\end{array}$ & 3.99 & 4.22 & .080 \\
\hline Q4. & $\begin{array}{l}\text { Chances of promotion in the Trust are } \\
\text { improved by working longer hours. }\end{array}$ & 4.75 & 4.73 & .884 \\
\hline Q5. & $\begin{array}{l}\text { I have unmet training needs on safety } \\
\text { issues }\end{array}$ & 4.40 & 4.18 & .144 \\
\hline Q6. & I feel valued at work & 3.88 & 3.72 & .339 \\
\hline Q7. & I feel positively challenged at work & 3.10 & 3.04 & 699 \\
\hline Q8. & $\begin{array}{l}\text { It is easy to maintain a work-life balance in } \\
\text { the Trust }\end{array}$ & 4.01 & 4.10 & .605 \\
\hline Q9. & $\begin{array}{l}\text { I am tempted to seek a job in a different } \\
\text { NHS Trust }\end{array}$ & 4.35 & 4.60 & .176 \\
\hline Q10 & $\begin{array}{l}\text { I am tempted to seek a job outside of the } \\
\text { NHS }\end{array}$ & 4.43 & 4.57 & .457 \\
\hline Q11 & $\begin{array}{l}\text { Personal achievements and successes are } \\
\text { acknowledged by the Trust }\end{array}$ & 3.76 & 3.98 & .145 \\
\hline Q12 & $\begin{array}{l}\text { Decisions made by managers reflect the } \\
\text { mission, objectives and values of the Trust }\end{array}$ & 3.71 & 3.62 & .602 \\
\hline Q13 & My values match those of the Trust & 3.30 & 3.38 & .451 \\
\hline
\end{tabular}

